\title{
Utilization of Cu-T in Paschim Midnapur district of West Bengal, India: An appraisal
}

\author{
Anima Haldar ${ }^{1}$, Samir Kumar Roy ${ }^{2}$, Tushar Kanti Saha ${ }^{3}$, Rama Prasad Roy ${ }^{4}$, Baijayanti Baur ${ }^{5}$, \\ Sanjay Kumar Saha ${ }^{6}$
}

${ }^{1}$ Professor and Head; ${ }^{3}$ Assistant Professor Community Medicine, Nilratan Sircar Medical College, Kolkata; ${ }^{2}$ Associate Professor, Community Medicine, Murshidabad Medical College, Berhampore $;{ }^{4}$ Associate Professor, Community Medicine, Malda Medical College, Malda; ${ }^{5}$ Professor \& Head, Community Medicine, Midnapore Medical College, Paschim Midnapore; ${ }^{6}$ Assistant Professor, Community Medicine, Bankura Medical College, Bankura, India.

\section{Abstract}

As a part of its commitment towards provision of quality spacing services in family planning, the Government of India introduced $\mathrm{Cu}-\mathrm{T} 380 \mathrm{~A}$ in 2002 with an effective protection for 10 years replacing the earlier $\mathrm{Cu}-\mathrm{T} 200 \mathrm{~B}$. In India, the use of the intrauterine device (IUD) is very low among married women of reproductive age, despite the fact that the Government offers IUD $(\mathrm{Cu}-\mathrm{T})$ services free of cost. The aim of the study was to assess the current status of intrauterine contraceptive device (Copper-T) utilization and to determine the relevant factors influencing utilization by currently married women of the reproductive age. The community-based cross-sectional study was carried out in 3 Blocks and 2 Municipality areas of the West Midnapur district in West Bengal. A multistage random sampling method was carried out to select villages of sub-center areas and wards from Municipality areas. A total of 16 areas were selected for the purpose of the study; 125 eligible couples from each selected area were interviewed by a house-to-house survey in order to cover 2000 eligible couples throughout the district. Only females were the respondents. It was found that $67.4 \%$ of the couples admitted to the use of any method of contraception. The Couple Protection Rate (by modern method) was found to be $62.6 \%$ in the study area. However, it was demonstrated that $\mathrm{Cu}-\mathrm{T}$ acceptance rate was only $1.3 \%$. Ligation (38.8\%) contributed the highest - other methods included: oral contraceptive pill $(19.4 \%)$, condom $(3 \%)$, vasectomy $(0.1 \%)$ and others $(4.8 \%)$. The ever use rate of intrauterine contraceptive device $(\mathrm{Cu}-\mathrm{T} / \mathrm{loop})$ in the study area was $6.2 \%$, which increased significantly with the advancement of maternal age, but no association was found with literacy status of the respondents. Lack of motivation (48.4\%), misconception (14\%), unawareness $(11.3 \%)$ unwillingness $(9.3 \%)$ and religious/cultural barrier $(2.4 \%)$ were the major factors for underutilization/non-utilization as elicited from the present study. Advocacy through mass media and sustenance of behavior change communication also needed for higher IUD utilization in both rural and urban area.

Keywords: Contraceptive practice, Awareness, Couple protection rate, $\mathrm{Cu}-\mathrm{T}$ utilization, India.

\section{Introduction}

India's population has crossed one billion in 2000 and is projected to reach 1.53 billion by 2050 , making it the most populous country in the world. ${ }^{1}$ Women of reproductive age group (15-49 years) make up approximately 248 million. ${ }^{1}$ The current approach in family planning emphasizes on offering high quality contraceptive services among eligible clients on a voluntary basis. ${ }^{1}$ An important component of the program is promoting adequate spacing of births. ${ }^{1}$

In India due to emphasis on sterilization, spacing methods have not been actively promoted nor are they easily available to those who are willing to adopt them. ${ }^{2}$ Despite the many advantages of the intrauterine device (IUD) as a method of family planning, it generally suffers from unpopularity worldwide, with the exception of few countries like China, Egypt, Mexico and Turkey. ${ }^{3}$ The scenario in India is the same, with less than $2 \%$ of currently women adopting the IUD as a method of contraception. ${ }^{3}$ As per National Family Health Survey-3, the contraceptive prevalence rate in India is $56.3 \%$, which varies widely among different states. ${ }^{1}$ But yet the

\section{Practice Points}

- In India, IUD utilization is very low among married women of reproductive age despite provision of free services by the government .

- The use of any method of contraceptive practice was recorded as $67.4 \%$ whereas Couple Protection Rate (modern method) was 62.6\% and Copper-T acceptance rate was only $1.3 \%$.

- Ever use rate of IUD (Cu-T/loop) was 6.2\%, which increases significantly with the advancement of maternal age.

- Lack of motivation (48.4\%), misconception (14\%), lack of awareness (11.3\%) and lack of willingness $(9.3 \%)$ were identified as the major factors for underutilization/non-utilization.

- Advocacy through mass media and sustenance of behavior change communication also needed for higher IUD utilization in both rural and urban area.

Correspondence: Dr. Tushar Kanti Saha, 2/4 MM Chandidas Road, Nabadwip (74130212), Nadia, West Bengal, India. E-mail: sahatusharkanti@gmail.com. 
acceptance of IUD $(\mathrm{Cu}-\mathrm{T})$ continues to remain below $2 \%$, out of total couple protection rate of $48.5 \%$ for the use of any modern contraceptive method (NFHS-3) in India. ${ }^{1}$

According to NFHS-3, the contraceptive prevalence rate by any method in West Bengal among currently married women aged $15-49$ yrs is $71 \%$ and couple protection rate by modern method is $50 \%{ }^{1}$ However, only $1 \%$ married women of reproductive age group currently adopted IUD in West Bengal. ${ }^{4}$ The knowledge of IUD has also declined from NFHS-2 (1998-1999) of $73 \%$ to $68 \%$ in NFHS-3 in the state. ${ }^{4}$

The government of India as part of its commitment towards provision of quality spacing services in family planning, introduced $\mathrm{Cu}-\mathrm{T} 380 \mathrm{~A}$ in 2002 with an effective protection for 10 years replacing the earlier $\mathrm{Cu}$ -T 200B. ${ }^{1}$ In India, only $1.8 \%$ of married women of reproductive age use IUDs, despite the fact that the Government offers IUD $(\mathrm{Cu}-\mathrm{T})$ services free of cost, it still remains largely underutilized. ${ }^{1}$ In India, a thorough review of birth spacing methods, especially IUDs, is needed since the record showed a declining trend of utilization and high rate of discontinuation. ${ }^{5}$ The aim of the present study was conducted with the objectives of assessment of current status of IUD $(\mathrm{Cu}-\mathrm{T})$ utilization and to determine the relevant factors influencing it in Paschim Midnapore district of West Bengal, India.

\section{Materials and methods}

A community-based cross-sectional study was carried out in rural and urban areas of Paschim Midnapore district of West Bengal, India during April to September 2009. The sampling technique used was a multistage stratified random sampling. Paschim Midnapore district was chosen randomly from the 19 districts. Out of total 29 blocks in the district, 3 were selected randomly from different subdivisions: Chandrakona-II in Ghatal subdivision, Keshpur in Sadar subdivision and Nayagram under Jhargram subdivision. In each block, 2 sub-centers were selected and in each sub-center, 2 villages were chosen by simple random sampling technique.

In the urban agglomerates, two municipalities (Kharagpur and Midnapore town) were selected randomly and again two wards had been chosen also by simple random sampling technique from each municipality. Thus we obtained 12 villages (4 villages from each block) and 4 urban wards, 2 wards from each municipality.

Since the average couple protection rate of West Bengal is $50 \%{ }^{4}$ and maximum allowable error is $5 \%$, minimum sample size works out to be 1600 . Hence the sample size was fixed at 2000 eligible couples for the study purpose. From each village/ward, 125 eligible couples were covered, so $(16 \times 125)$ total 2000 currently married women of reproductive age constitutes the study population. Data were collected through pre-designed and pre-tested schedule by interviewing the female partner of all eligible couples in a house-to-house survey following standard random procedure to go to the first house. Faculty members of the Community Medicine Department of different medical colleges were involved in the survey. Supervision was also done by senior faculty members of different medical colleges of West Bengal.

The study variables included age of respondent and as well as her husband, type of family, religion, age at marriage, parity, occupation and literacy status of wife and husband, per capita monthly income, number of living children, knowledge about IUD, current use of contraceptive, ever use of IUD, reasons for non-use of $\mathrm{Cu}-\mathrm{T}$ etc. Data analysis was done by Microsoft Excel, Epi-Info (3.5.1) software with standard statistical test.

The definitions of the key terminology used in the study are as follows:

Eligible Couple: Couples with Wives aged between 1549 years who will be needing family planning services are referred to as eligible couples. ${ }^{6}$

Currently married women: Married women of reproductive age group of 15-49 years living with their husband at present. ${ }^{6}$

Contraceptive Prevalence rate: Percentage of couples who were covered by any method (modern method and traditional method) of family planning measures. ${ }^{6}$

Couple Protection rate: Percentage of eligible Couples effectively protected against child birth by one or the other approved methods of family planning e.g. sterilization, IUCD, condom, oral pills. ${ }^{6}$

Influencers: Influencers are the persons from the community who act as motivators for the purpose for which they are engaged.

\section{Results}

Out of total study population of 2000 eligible couples, only $1348(67.4 \%)$ eligible couples practiced any method (modern as well as traditional/miscellaneous method) of contraception. Couple protection rate (percentage of couples protected by modern methods) was found $62.6 \%$ (1266 eligible couples protected by modern methods out of 2000 eligible couples).

In the present study, it was revealed that only $1.3 \%$ of the respondents (currently married women of reproductive age group) adopted $\mathrm{Cu}-\mathrm{T}$ as family planning measures (Table 1). There was also area specific variation of $\mathrm{Cu}-\mathrm{T}$ acceptance, in rural area Copper- $\mathrm{T}$ adopters were more $(1.5 \%)$ than urban area $(0.8 \%)$ but this difference was not statistically significant $(p-0.314)$. (Table 2)

Table 1 also indicates that out of total eligible couples, $32.6 \%$ were not using any method of contraception whereas majority (38.8\%) had ligation followed by 
Table 1: Practice of family planning methods by the respondents

\begin{tabular}{|l|c|}
\hline \multicolumn{1}{|c|}{ Methods } & Respondents (\%) \\
\hline Oral contraceptive pill & $388(19.4 \%)$ \\
\hline Cu-T & $26(1.3 \%)$ \\
\hline Condom & $60(3.0 \%)$ \\
\hline Vasectomy & $2(0.1 \%)$ \\
\hline Ligation & $776(38.8 \%)$ \\
\hline Not using any methods & $652(32.6 \%)$ \\
\hline Others & $96(4.8 \%)$ \\
\hline
\end{tabular}

$19.4 \%$ used to take oral contraceptive pill (OCP). Other methods included condom (3\%), Cu-T (1.3\%), vasectomy $(0.1 \%)$ and others miscellaneous/traditional methods $(4.8 \%)$.

Out of total respondents, only 125 women used $\mathrm{Cu}-\mathrm{T}$ in their reproductive life time (ever use rate of $\mathrm{Cu}-\mathrm{T}$ was $6.2 \%$ ). Out of them, $8.7 \%$ were in the age group of less than 18 years and $4.8 \%, 5.5 \%, 9.5 \%$ and $5.4 \%$ were in the age group of 18-23 years, 24-29 years, 30-35 years and 36 years or more respectively. The difference was found to be statistically significant $\left(\chi^{2}-8.48, p-0.037\right.$, df3 ) (Table 2). The ever used rate of $\mathrm{Cu}-\mathrm{T}$ increases with advancement of maternal age and the association being statistically significant $(\mathrm{p}<0.05)$.

There was slight variation in acceptance of $\mathrm{Cu}-\mathrm{T}$ according to literacy status of the respondents. Acceptance among educated group was more than illiterate and just literate group shown in Table 2 but these difference was not statistically significant $\left(\chi^{2}-1.42, p\right.$ 0.49 ). It has been observed that only $11.6 \%$ of the respondents knew about the advantages of $\mathrm{Cu}-\mathrm{T}$.
Area specific couple protection rate and current $\mathrm{Cu}-\mathrm{T}$ use rate was shown in Table 3 . Both couple protection rate $(76 \%)$ and $\mathrm{Cu}-\mathrm{T}$ use rate $(3.1 \%)$ was highest in Chandrokona-II Block whereas CPR (46\%) lowest in Nayagram Block but lowest $\mathrm{Cu}-\mathrm{T}$ use rate observed in urban Kharagpur municipality area. Copper-T utilization rate varied in different areas throughout the district of West Midnapur and more utilization observed in rural area than the urban area.

The reasons for non-utilization of $\mathrm{Cu}-\mathrm{T}$; the major factors were lack of motivation (48.8\%), misconception (harmful for health, misbelieves, wrong information) $(13.9 \%)$, and lack of awareness $(11.3 \%)$. Area-wise reasons for non-utilization of $\mathrm{Cu}-\mathrm{T}$ are shown in Figure 1. In rural area, lack of awareness (47\%), lack of motivation $(44.6 \%)$, and misconception $(13.6 \%)$ were the major causes of non-utilization of $\mathrm{Cu}-\mathrm{T}$. In urban area, lack of motivation (51.6\%), lack of awareness $(18.9 \%)$ and misconception $(14.5 \%)$ was the major factor for non-utilization of $\mathrm{Cu}-\mathrm{T}$.

\section{Discussion}

The present study was carried out among 2000 eligible couples to find out the relevant factors responsible for underutilization of IUD in rural and urban areas of Paschim Midnapore district of West Bengal, India. The contraceptive prevalence rate/family planning practice by any method was detected $67.4 \%$ in the present study which was less than the findings of NFHS-3 of West Bengal (2005-2006) where it was 71.2\%. ${ }^{4}$ But couple protection rate by modern method was found $62.6 \%$ in the district of Paschim Midnapore, higher than the NFHS-3 of West Bengal $(50 \%) .{ }^{4}$ A study conducted by $\mathrm{Thalji}^{7}$ in Tafila-Jordan showed the prevalence rate of

Table 2: Age, education and practice of family planning methods by the respondents

\begin{tabular}{|c|c|c|}
\hline Criteria & No of Respondents (\%) & Statistical tests \\
\hline \multicolumn{3}{|c|}{ Age-wise distribution of respondents according to ever use of IUCD } \\
\hline$<18(\mathrm{n}-23)$ & $2(8.7 \%)$ & \multirow{5}{*}{$\chi^{2}=8.48, p=0.037, d f=3$} \\
\hline $18-23(n-452)$ & $22(4.8 \%)$ & \\
\hline $24-29(n-630)$ & $35(5.5 \%)$ & \\
\hline $30-35(n-381)$ & $36(9.5 \%)$ & \\
\hline$\geq 36(n-514)$ & $30(5.4 \%)$ & \\
\hline \multicolumn{3}{|c|}{ Literacy wise distribution of respondents according to ever use of IUCD } \\
\hline Illiterate and just literate (n-939) & $54(5.7 \%)$ & \multirow{4}{*}{$\chi^{2}=1.42, p=0.49, \mathrm{df}=2$} \\
\hline Primary $(n-436)$ & $26(5.9 \%)$ & \\
\hline Secondary and above (n-625) & $45(7.2 \%)$ & \\
\hline Total $(\mathrm{n}-2000)$ & $125(6.2 \%)$ & \\
\hline \multicolumn{3}{|l|}{ Practice of $\mathrm{Cu}-\mathrm{T}$ by the respondents } \\
\hline Rural (n-1500) & $23(1.5 \%)$ & \multirow{2}{*}{$\begin{array}{l}\chi^{2}=1.01, p=0.314, \mathrm{OR}=1.93, \\
\mathrm{RR}=1.92, \text { Taylor Series } 95 \% \mathrm{CI}\end{array}$} \\
\hline Urban $(n-500)$ & $4(0.8 \%)$ & \\
\hline
\end{tabular}

Table 3: Area specific couple protection rate and current $\mathrm{Cu}$ - $\mathrm{T}$ use rate by the respondents

\begin{tabular}{|l|c|c|c|c|c|c|}
\hline \multicolumn{1}{|c|}{ Area/Indicators } & $\begin{array}{c}\text { Nayagram } \\
\text { Block }\end{array}$ & $\begin{array}{c}\text { Chandrakona } \\
\text { II Block }\end{array}$ & $\begin{array}{c}\text { Keshpur } \\
\text { Block }\end{array}$ & $\begin{array}{c}\text { Kharagpur } \\
\text { Municiplaty }\end{array}$ & $\begin{array}{c}\text { Midnapur } \\
\text { Municiplaty }\end{array}$ & Total \\
\hline Couple Protection Rate & $46 \%$ & $76 \%$ & $63.8 \%$ & $58.4 \%$ & $70 \%$ & $62.6 \%$ \\
\hline Present $\mathrm{Cu}-\mathrm{T}$ use rate & $0.8 \%$ & $3.14 \%$ & $2.8 \%$ & $0.7 \%$ & $1.7 \%$ & $1.3 \%$ \\
\hline
\end{tabular}




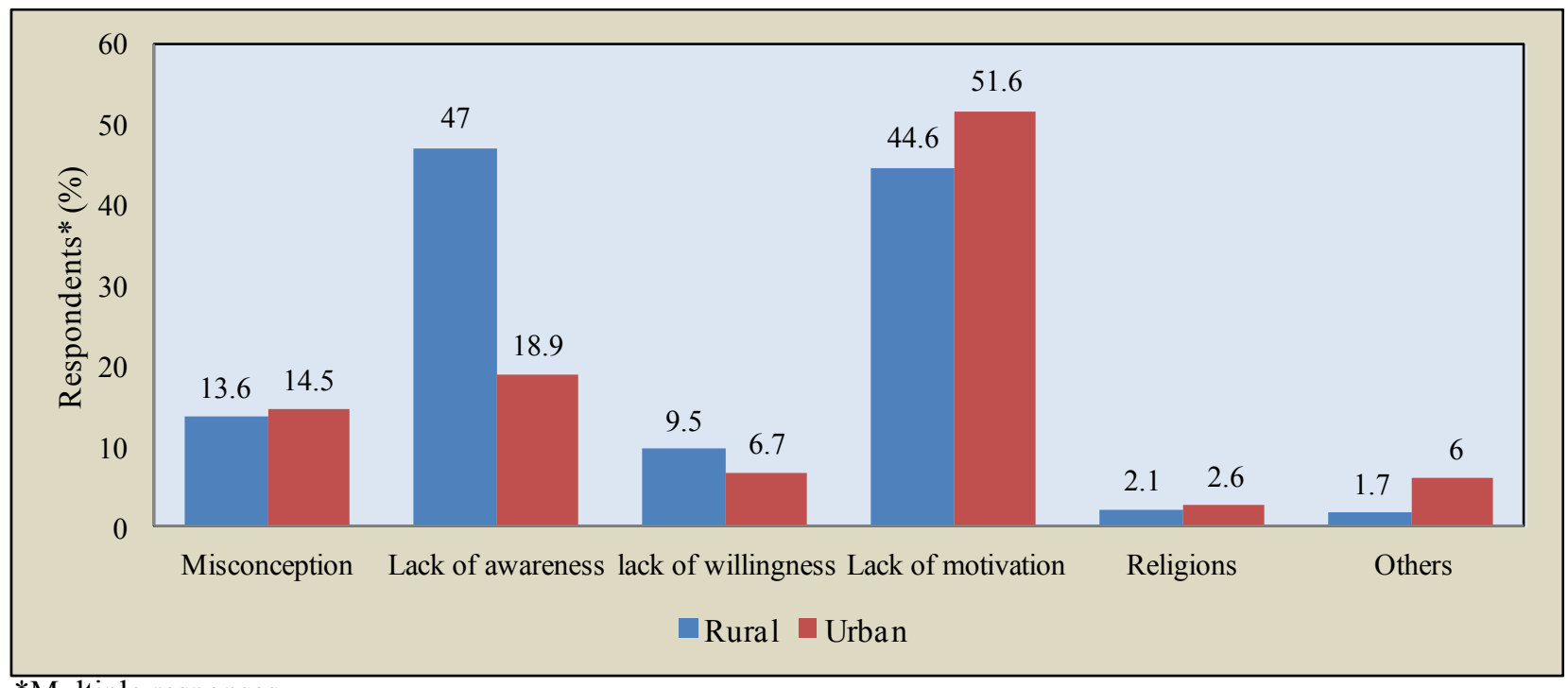

*Multiple responses

Fig 1: Area-wise reasons for non-utilization of $\mathrm{Cu}-\mathrm{T}$ in Paschim Midnapore district

contraceptive use was $38.3 \%$, but in this study IUCD was the most commonly used method. The present study showed that both contraceptive prevalence rate $(67.4 \%)$ and couple protection rate $(62.6 \%)$ were higher than the national figure of $56.3 \%$ and $48.5 \%$ respectively as per NFHS-3 (2005-2006). ${ }^{1}$

In the present study, overall use rate of IUCD (CopperT) was found to be $1.3 \%$. In India, It was found that only $1.8 \%$ of married women of reproductive age group use Copper- $\mathrm{T}^{3}$ and the practice in West Bengal was only $1 \%{ }^{4}$ Tuladhar \& Marahtta ${ }^{8}$ demonstrated the Copper-T utilization rate of $2.5 \%$ in a study conducted in Nepal.

Contribution of couple protection rate of the present study highlighted that maximum contribution by ligation (38.8\%) followed by oral contraceptive pill (19.4\%). , These findings corroborated with the findings of NFHS-3 of National figure except OCP; of the couple protection rate was $48.5 \%$ and the maximum contribution were by ligation $(37.3 \%)$, condom $(5.3 \%)$ and OCP $(3.1 \%){ }^{3}$

Though the present study revealed that $11.6 \%$ of the respondents were aware about advantages of Copper- $\mathrm{T}$, however the ever use rate $(6.2 \%)$ and current acceptance rate of Copper-T $(1.3 \%)$ were found to be low. It has been also observed that ever use rate of $\mathrm{Cu}-\mathrm{T} / \mathrm{loop}$ increased with advancement of maternal age, similar observations also found in earlier study conducted in Manipur, India. ${ }^{9}$ A variation in ever use rate of Coppr-T in relation to literacy status was noted in the present study; this observation did not correspond with the findings of the earlier studies by Mukhopadhyay et al. ${ }^{10}$ and Sharma et al. ${ }^{11}$

The relevant factors for non-utilization of $\mathrm{Cu}-\mathrm{T} / \mathrm{loop}$ were elicited from the present study. Lack of motivation, misconception, lack of awareness, unwillingness and religious/cultural barrier was the main reasons irrespective of residence of the study population. More or less similar observations were also found by the earlier studies conducted in India. ${ }^{12-16}$ In an earlier study conducted in both rural and urban area of Vadodara District, Gujarat revealed that demand generation activities and provision of good quality services, together with a supportive programmatic environment, simultaneously would increase IUCD acceptance. ${ }^{3}$ But lack of awareness (47\%) was the main reason in rural area and it was much greater than urban area (18.9\%). Religious/Cultural barrier was cited/ commented by $2.1 \%$ of the respondent in rural area for their non-utilization of $\mathrm{Cu}-\mathrm{T}$ whereas in urban area it was expressed by $2.6 \%$ of the respondent only.

It was revealed by the present study that unawareness, misconception and unwillingness were commented as reasons by more or less of equal proportion of the respondents irrespective of rural or urban area for their non-utilization of $\mathrm{Cu}$-T services though it was supplied free of cost by the Government.

In urban area, lack of motivation and unawareness were the major reasons, it may be due to lack of organized health care services and limited educational materials to provide accurate information about the method to clients, and also no and limited involvement of mass media to highlight family planning services. In rural area unawareness, lack of motivation and misconception about the method may be due to lower literacy level, and myths and misconception about the methods may also due to lack of information education communication (IEC) and less advocacy. There was very little motivation to health care providers to promote the $\mathrm{Cu}-\mathrm{T}$ or other temporary methods due to over emphasis on sterilization by national programs.

\section{Conclusion}

It can be concluded from the present study that, due to an increased emphasis on permanent methods, the adoption of temporary methods is neglected in the Paschim Midnapur district. The utilization rate of $\mathrm{Cu}-\mathrm{T}$ and the factors for non utilization varied throughout the 
district. Awareness regarding contraception should be generated through interpersonal communication involving trained health service providers and religious leader in both urban and rural area along with advocacy through mass media. Sustained and coherent area specific behavior change communication efforts are required for better utilization of IUD. Awareness about small family norm, adoption of both temporary and permanent methods at the appropriate time as well as improvement of literacy status is essential for reduction of population growth.

\section{Acknowledgement}

The authors gratefully acknowledge the financial support from State Family Welfare Bureau, West Bengal, India. The authors are thankful to the district officials and field staff for their active cooperation and support. The authors are also thankful to the Principal of National Medical College, Kolkata for allow us to conduct the research study

\section{Competing Interest}

The authors have declared that no competing interests exist.

\section{References}

1. Ministry of Health and Family Welfare. IUCD Reference Manual for Medical Officers, Family Planning Division. New Delhi: Ministry of Health and Family Welfare, 2007.

2. Thiagarajan BP, Adhikari MR. The level of unmet need and its determinants in Uttar Pradesh. $J$ Family Welfare 1995;41(4): 66.

3. Khan ME, Kar SSDesai VK, Patel P. The model works! Repositioning of IUD in Public Health Programme in India. Research Update no 12. New Delhi, 2007.

4. National Family Health Survey (NFHS-3) West Bengal. Knowledge of Family Planning methods. Mumbai: International Institute for Population Sciences, 2006.

5. Salhan S, Tripathi V. Factors influencing discontinuation of intrauterine contraceptive devices; an assessment in the Indian context. Eur J Contracept Reprod Health Care 2004; 9(4):245-59.

6. Park K. Textbook of Preventive and Social Medicine. 20th Edition. Jabalpur: Banaraidas Bhanot, 2009.
7. Thalji NN. Knowledge, attitude and practice of women towards family planning methods in Tafila-Jordan. JRMS 2003;10(1): 40-4.

8. Tuladhar H,Marahatta R. Awareness and practice of family Planning methods in women attending Gyne OPD at Nepal Medical College Teaching Hospital. Nepal Med Coll J 2008;10(3):184-91.

9. Singh NKR, Devi IT, Devi BT, Singh MY, Devi NT, Singh SN. Acceptability of contraceptive methods among urban Eligible Couples of Imphal, Manipur. IJCM 2004;29(1):13-7.

10. Mukhopadhyay SP, Halder AK, Das KK. A study of utilization of Family planning services through $\mathrm{MCH}$ package care in rural area of West Bengal. Indian J Public Health 1990;34:147-51.

11. Sharma AK et al, Pattern of Contraceptive use by residents of a village in South Delhi; IJPH 1997 , 41(3); 75-8.

12. Santhya KG. Changing family planning scenario in India; An overview of recent evidence. Regional Working Paper. New Delhi: Population Council, 2003.

13. Mishra VK, Retherford RD, Nair PS, Feeney G. Reasons for discontinuing and not intending to use contraception in India. National Family Health Survey Report. Mumbai: International Institute for Population Sciences, 1999.

14. Khan et al. The quality of Family planning Services in Uttar Pradesh from the perspective of service providers. In: Michael A, Koenig, M.E. Khan (ed.). Improving quality of Family Welfare Programme in India. New Delhi: Population Council, 1999, p. 238-69.

15. International Institute for Population Sciences and Macro International. National Family Health Survey (NFHS - 3), India, Mumbai, 2005-2006. Vol. 1. Mumbai: International Institute for Population Sciences and Macro International, 2007.

16. Gandotra MM, DAS NP. Factors influencing choice of contraceptive and the reasons for its discontinuation. In: ME. Khan, G Cernada. Spacing as an alternative strategy: India's Family Welfare Programme Survey (NFHS-3), 20052006. Vol. 1. Mumbai: IIPS.B.R. Publishing Corporation, 2007. 